(Horne's). One hundred cubic centimeters of the milk were taken and $3 \mathrm{~g}$. of the acetate accurately weighed and added, thoroughly shaken and filtered to $50 \mathrm{cc}$. Readings were then made on the clear sera.

The determinations made on laboratory samples I to I6 show a fair degree of uniformity. It will be observed from a comparison of the conductivity and the chemical analysis, that the differences in fat and total solids content bear no relation to the differences in conductivity. The sera from authentic samples I 8 to 23 show a far greater variation than has been observed in any of the foregoing determinations and the results are entirely unreliable.

In the authentic samples adulterated in the laboratory ( 24 to 29 ) the water was first added to the samples and $100 \mathrm{cc}$. of the adulterated milk were then taken and coagulated as described above.

These results show great differences, even at the same adulteration and these differences are greater than those between the authentic and adulterated samples. This is probably due to an irregular adsorption of the lead salt by the coagulum, which would account for the lack of uniformity in the results, as was the case in experiments mentioned under Method I at the beginning of this paper.

Having tried out the method and investigated all of the modifications at hand in a most exhatustive manner and being unable to obtain any uniformity in results it was decided to abandon the method as impractical.

It is to be regretted that this method proved ineffective, as a rapid and accurate method of this sort would be of great value to the food analyst.

One of the authors, Durand, proposes at an early date to continue this research, making use of the osmotic pressure of milk, in a cell specially constructed to measure the differential osmotic pressure between milks and a standard saline solution.

$$
\begin{gathered}
\text { Chamical, Laboratory, DePartiment OF HealTh } \\
\text { AND } \\
\text { COLLEGE OF THE CITY OF NEW YORK } \\
\text { NEW YORK CITY }
\end{gathered}
$$

\section{THE LOGANBERRY AND THE ACID CONTENT OF ITS JUICE}

\section{By Milo Reason Daughters}

Received September 24, 1917

Attention has been called to the composition of loganberry pulp and juice and to the drying properties of loganberry oil. ${ }^{1}$ This paper gives the composition of the fresh, ripe, whole berry and some data on the juice, with special reference to its acid content.

TABLE I-COMPOSITION OF THE LOOANBERRY2

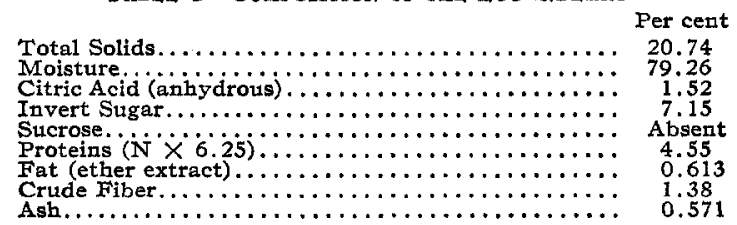

1 This Journal, 9 (1917), 1043.

Colby reported the analysis of a sample of California loganberries. California Experiment Station Report, 1895, 177.
The sample (Table I) was taken from $\mathrm{I}_{4} \mathrm{lbs}$. of berries gathered at the close of a uniformly dry season. Total moisture was obtained by heating in vacuo at $70^{\circ} \mathrm{C}$. to constant weight. An electric muffle furnace heated to dull redness was used for the ash determinations. Citric acid was estimated by the method given in the Journal of the Association of Official Agricultural Chemists, Vol. 2 (I916), 183.

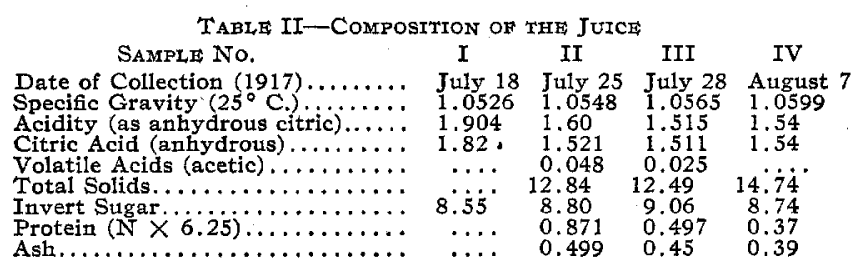

The first three samples of juice were pressed from 4 to $5 \mathrm{lbs}$. of berries purchased in the open market. The berries were ground in a food chopper and then pressed in a small fruit press lined with doubled bird's-eye cotton cloth. Sample IV was obtained in a similar manner in a larger press from $\mathrm{I} 4 \mathrm{lbs}$. of berries after removing the sample for the analysis given in Table I. The specific gravity readings were made by the pycnometer method on the juice which was kept in a constant temperature bath at $25^{\circ} \mathrm{C}$.

Dunbar and Lepper ${ }^{1}$ have made a study of the $\mathrm{Kunz} \mathrm{z}^{2}$ modification of Stahre's method ${ }^{3}$ for the quantitative estimation of citric acid and have announced its applicability to fruit products. This method was applied directly to the juice without preliminary precipitation of the citric acid as the barium salt in the last three samples. Twenty-five grams of juice were placed in a volumetric flask of Ioo cc. capacity, and 2 cc. of dilute sulfuric acid and $5 \mathrm{cc}$. of freshly prepared bromine water added, and then made up to the mark with distilled water. Aliquots of $25 \mathrm{cc}$. each were used in the analysis. Approximately $40 \mathrm{cc}$. of 5 per cent potassium permanganate were required to complete the oxidation of the citric acid, pectins, sugars, etc. Pentabromacetone separated in a very satisfactory manner as a white semicrystalline solid, leaving a clear supernatant liquid after the addition of ferrous sulfate.

Samples II and III were examined for volatile acids, which were found to be present in traces. Tartaric acid was found in traces by Jorgensen's method.4 Dunbar and Bacon's ${ }^{5}$ uranyl acetate method for malic acid was tried on Sample I, but with negative results.

In conclusion, it may be stated that citric is the chief acid of the loganberry. Traces of tartaric and volatile acids are also present. Malic acid is absent. DEPARTMENT OF CHEMISTRY

Oragon State Agricultural Coliege Corvalisis

1 Jr. A. O. A. C., 3 (1916), 182; No. 4 (1917), 175.

2 Arch. Chem. Mikros., 7 (1914), 285; Chem. Abs., 9 (1915), 687.

- Nordisk Tidsskrift, 2 (1895), 141; Z, anal. Chem., 36 (1897), 195.

Z. Nahr. Genussm., 17 (1909), 397; Abderhalden, "Handbuch Biochem. Arbeitsmeth." 2 (1910), 35; Chem. Abs., 3 (1909), 1781.

s U. S. Dept. of Agr., Bureau of Chemistry, Circular 76; Jr. A. O. A. C., 2 (1917), 179; ThIS JoURNAL, 3 (1911), 826. 